\title{
Crítica biográfica fronteiriça
}

\section{Edgar Cézar Nolasco}

Brasil. Universidade Federal de Mato Grosso do Sul/NECC, Universidade Federal do Rio de Janeiro/PACC. ecnolasco@uol.com.br 
Descubrimos em ese proceso la diferencia colonial y descubrimos que vivir en y vivir la diferencia colonial es vivir em las fronteras; descubrimos también em la experiencia del vivir en las fronteras que nuestras formas de pensar son fronterizas, ya no territoriales, han escapado de la cámara oscura com muchos colores. Em ese momento nos damos cuenta de que se nos ha dado um vuelco em nuestras formas de pensar, de estar siendo y de sentir, el vuelco de la razón (MIGNOLO, 2011, p. 11).

Vou começar meu texto com duas passagens que, cada uma a seu modo, ilustram a discussão que quero propor acerca de uma crítica biográfica fronteiriça.

A primeira passagem eu a colhi no livro Ignorância do sempre, do filósofo Juliano Garcia Pessanha:

\begin{abstract}
Enquanto a aranha cerzia o frágil arabesco da sua teia, vi que a imensidão da noite circundante permanecia atravessando todas as linhas brancas do traçado e que ela passeava dentro da doçura de um abismo. Lembrei-me então de uma maravilha cujo nome é homem e descobri o segredo de uma afinidade! Se a aranha faz a teia, o homem tece biografia. Biografia é a tristeza de não ter podido residir no elemento negativo: se o homem foi constrangido a abandonar a 'simplicidade da noite' pela loucura do nascimento, ele pode, numa rememoração permanente do oculto, suportar a luz cansada que vigora na passagem pelo exílio deste mundo (PESSANHA, 2000, p. 46).
\end{abstract} fazedor:

A segunda passagem eu busco no epílogo que Jorge Luis Borges faz ao livro $O$

Um homem se propõe a tarefa de desenhar o mundo. Ao longo dos anos, povoa um espaço com imagens de províncias, de reinos, de montanhas, de baias, de naus, de ilhas, de peixes, de moradas, de instrumentos, de astros, de cavalos e de pessoas. Pouco antes de morrer, descobre que esse paciente labirinto de linhas traça a imagem de seu rosto (BORGES, 2008, p. 168).

Enquanto na primeira passagem, a imagem da aranha contém uma primeira descrição pós-metafísica do ser humano, remetendo-nos ao fora, ou, como quer a discussão de base pós-colonial que proponho, ao exterior (à exterioridade), na segunda passagem temos a presença do bios inscrita na produção cultural e 
epistemológica do intelectual, às vezes, inclusive, à sua revelia. Esta outra passagem de Pessanha mostra a aproximação que fazemos entre a visada pós-metafísica e a pós-colonial:

\begin{abstract}
Mas se a metafísica da presença pensou apenas o Dentro, devemos, agora, começar a pensar o Fora. E devemos fazê-lo não porque isso seja apenas uma novidade ou um pensamento diferente no mercado das ideias. Não: pensar o Fora não é produzir mais um pensamento para enriquecer o estoque da cultura, mas operar uma mutação na nossa maneira de existir. Somos, hoje, eticamente forçados a pensar diferente, porque estamos, pela primeira vez, numa situação capaz de perceber a violência e a agressão que dormitavam no pensamento metafísico (PESSANHA, 2000, p. 101-192).
\end{abstract}

O que está envolto à discussão não é uma visada dualista acerca da existência ou não de dentro e fora, de centro e periferia, posto que haja um consenso de que há toda uma exterioridade que simplesmente não foi contemplada pelo projeto moderno do sistema colonial. Nessa direção, destaco uma nota feita por Mignolo, em seu livro Histórias locais/Projetos globais, que ajuda a entender a questão:

Disseram-me uma ou duas vezes que não deveria falar de Primeiro, Segundo e Terceiro Mundos porque tais entidades nunca existiram. Gostaria de salientar que não estou falando sobre a entidade, mas sobre a divisão conceitual do mundo, que, como tal, existiu e continua existindo, mesmo que a configuração do mundo já não seja a mesma que originou a classificação. Sinto-me obrigado a desculpar-me por introduzir esta nota, mas ao mesmo tempo não posso evitá-la (MIGNOLO, 2003, p. 162).

Todavia, a fronteira-Sul do Brasil, de onde erijo minha discussão, por exemplo, não é a fronteira-Norte. Os eixos, ou centros desenvolvidos do país, não são iguais às margens periféricas. Nem mesmo as periferias dos grandes centros urbanos do país são iguais às periferias geoistóricas e territoriais. A fronteira-Sul Brasil/Paraguai/Bolívia tem suas questões culturais e políticas bem postas no contexto socioeconômico, político e cultural, apesar de, ao olhar imperial dos centros, continuar na escuridão. Por conseguinte, tal lócus demanda um posicionamento crítico específico para, assim, aferir melhor suas especificidades. Nessa direção, só se é possível pensar e, por extensão, discutir acerca da fronteira-Sul a partir da fronteira-Sul. E não estou pensando em termos de localização territorial apenas; 
muito pelo contrário, estou afirmando que tal discussão hoje, e cada vez mais, demanda do crítico um posicionamento assentado em uma epistemologia fronteiriça. Conceitualmente o mundo e os países estão claramente divididos e, por extensão, os valores econômicos, estéticos, o poder e o saber muito mal distribuídos entre as regiões e os centros de um país territorialmente imenso como o Brasil. Há uma ignorância para sempre posta (parafraseando o título do livro de Pessanha) nas distribuições de poder e de saber dentro do país, como se as margens longínquas também não gerassem saberes e valores. Além do descaso dos órgãos de fomento (e o descaso dá-se pela equiparação entre todas) para com as universidades periféricas, como a na/da qual trabalho, penso e escrevo (UFMS), por exemplo, tais universidades parecem estar condenadas a repetir incansavelmente as lições aprendidas nos grandes centros do país e do mundo. Mesmo hoje, em pleno século 21, há uma política crítica intelectual no Brasil que entende que seu papel é o de ainda revisitar criticamente conceitos pensados fora (Europa e Estados Unidos) e simplesmente repassá-los para as regiões ex-cêntricas do país, ao invés de propor um diálogo crítico mais interessante e vivo entre as epistemologias dos centros (importadas ou não) e as que têm emergido das regiões mais equidistantes desse país colossal.

Acerca dessa aparente dualidade que ainda ronda os discursos modernos que teimam em continuar a não ver a emergência de epistemologias que emergem das exterioridades, Mignolo parece sintetizar a discussão no último parágrafo de seu livro Histórias locais $\mid$ Projetos globais:

Dentro e fora, centro e periferia são metáforas dúplices que dizem mais sobre os loci da enunciação do que sobre a ontologia do mundo. Há e não há dentro e fora, centro e periferia. 0 que realmente existe é a fala de agentes que afirmam ou negam essas oposições dentro da colonialidade do poder, da subalternização do conhecimento e da diferença colonial. 0 último horizonte do pensamento liminar não está atuando apenas em direção a uma crítica de categorias coloniais; está atuando também no sentido de reverter a subalternização dos saberes e a colonialidade do poder. Também indica uma nova maneira de pensar na qual as dicotomias podem ser substituídas pela complementaridade de termos obviamente contraditórios. 0 pensamento liminar poderia abrir as portas para uma outra língua, um outro pensamento, uma outra lógica, superando a longa história do mundo colonial moderno, a 
colonialidade do poder, a subalternização dos saberes e a diferença colonial (MIGNOLO, 2003, p. 454).

O lócus geoistórico cultural fronteiriço de onde penso, trabalho e escrevo, ou seja, a fronteira-Sul que compreende os países Brasil (mais precisamente o estado de Mato Grosso do Sul), Paraguai e Bolívia, se, por um lado, marca e situa meu bios no contexto cultural brasileiro, por outro lado, permite a inserção e a delimitação de meu lócus como condição sine qua non para as reflexões críticas que proponho a partir desse lugar fronteiriço.

Até aqui, procurei pontuar tão somente duas questões as quais vejo como essenciais para a discussão que proponho e que atende pela rubrica de Crítica Biográfica Fronteiriça. Trata-se do que passo a denominar de (bios=vida + lócus=lugar) biolócus. Por essa conceituação compreendo, então, a importância de se levar em conta numa reflexão crítica de base fronteiriça tanto o que é da ordem do bios (quer seja do “objeto” em estudo, quanto do sujeito crítico envolvido na ação), quanto da ordem do lócus (o lugar a partir de onde tal reflexão é proposta). Nessa direção, pensar a partir da fronteira-Sul faz, sim, toda a diferença colonial. ${ }^{1}$

Assim, a partir do bios e do lócus das vidas encenadas na fronteira, a partir do momento em que "as vidas na fronteira"2 são concebidas e experimentadas por meio de uma perspectiva outra, assim como as culturas nativas do povo desse biolócus, erige-se uma crítica outra que formula e propõe uma "epistemologia fronteriza" na qual, segundo Mignolo, a reflexão, incorporada nas histórias locais, encontra seu lugar no conhecimento desincorporado dos projetos globais em ciências sociais ${ }^{3}$. Por sua vez, as histórias locais fronteiriças, incluindo aí o sujeito e as produções culturais desse

\footnotetext{
1 "Conforme as defino, as 'diferenças coloniais' significam, em todo meu argumento (talvez eu devesse dizer 'a diferença colonial'), a classificação do planeta no imaginário colonial $\backslash$ moderno praticada pela colonialidade do poder, uma energia e um maquinário que transforma diferenças em valores." (MIGNOLO, 2003, p. 36-37)

${ }^{2}$ Ver MIGNOLO, 2003, p. 340. Bhabha, no início de sua Introdução ao livro O local da cultura (2003), cujo subtítulo se intitula precisamente de "Vidas na fronteira: a arte do presente", adverte-nos de que "nossa existência hoje é marcada por uma tenebrosa sensação de sobrevivência, de viver nas fronteiras do 'presente', para as quais não parece haver nome próprio além do atual e controvertido deslizamento do prefixo “pós': pós-modernismo, pós-colonialismo, pós-feminismo...” (BHBHA 2003, p. 19).

3 "El libro de Anzaldúa Bordelands/La frontera no solo es um momento teórico fundamental para la construcción de categorias geo-culturales no imperiales, sino que lo es precisamente por indicar uma dirección posible para la superación del occidentalismo. Anzaldúa muestra la necesidad de uma epistemologia fronteriza, posoccidental, que permita pensar y construir pensamiento a partir de los interstícios y que pueda aceptar que los inmigrantes, refugiados, los homosexuales, etc., son categorias fuera d ela ley desde uma epistemologia monotópica que normaliza determinados espacios (nacionais, imperiales), como espacios de contención y de marginación." (MIGNOLO, 1998, s.p.)
} 
indivíduo, como consequência natural do biolócus, só podem ser alcançadas por meio de uma reflexão crítica assentada em uma epistemologia fronteiriça, cuja proposta, ou opção descolonial, reside para além de quaisquer binarismos.

A visada teórica defendida pela crítica biográfica fronteiriça se, por um lado, não ignora as demais abordagens teórico-críticas, como a moderna e ocidental, por outro lado, entende que é por meio da articulação de uma epistemologia fronteiriça que se pode compreender e abarcar melhor as histórias locais desses loci epistemológicos e suas produções que continuam não encampados pelas críticas modernas geralmente pensadas dos grandes centros do país e do mundo moderno. 0 intelectual crítico fronteiriço aprendeu que somente uma crítica desse lócus pode considerar em suas discussões as sensibilidades biográficas e locais dos sujeitos e das produções envolvidas, inclusive do próprio intelectual que optou por aprender a desaprender as lições canonizadas e cristalizadas nas bordas dos pensamentos fronteiriços. Esse crítico sabe da importância de sua inscrição na discussão prática teórica defendida por ele, sabe que, ao agir assim, não cai na velha prática herdada pelas bordas do grande centro moderno de repetir à exaustão uma lição teórica falida e põe em execução uma teorização pós-colonial (MIGNOLO) que se articula por fora das demais teorias aquilatadas dentro do grande sistema moderno que ensombrou o mundo até o final do século 20.

Não por acaso Mignolo propõe uma distinção significativa entre teorias póscoloniais, de um lado, e teorização pós-colonial, de outro. Enquanto as primeiras não passam de "uma mercadoria acadêmica", e talvez por estarem presas a uma visada acadêmica e disciplinar tão comum no meio acadêmico, o lugar por excelência das áreas humanas, no qual as disciplinas ainda parecem ter um lugar e um discurso teórico específico, a teorização pós-colonial "são críticas incluídas na razão subalterna e na gnose liminar: um processo de pensamento que os que vivem sob a dominação colonial precisam empreender para negociar suas vidas e sua condição subalterna." (MIGNOLO, 2003, p. 146) Nessa direção, a fronteira-Sul que contempla a discussão aqui proposta apresenta-se como uma paisagem crítica específica para receber e, ao mesmo tempo, propor uma crítica cuja epistemologia fronteiriça engendra uma teorização pós-fronteiriça que começa precisamente pelo bios dos sujeitos envolvidos (incluindo o crítico). A própria condição de se encontrar, ou de 
habitar na fronteira (alusão ao livro de Mignolo), ou de viver e pensar desse lócus geoistórico, já demanda um posicionamento crítico, ou opção descolonial, da reflexão erigida dessa zona fronteiriça, como forma de não barganhar as vidas da \na fronteira como tem feito costumeiramente as teorias itinerantes que migram dos centros para as bordas. Na esteira do que propõe Mignolo, a teorização pós-colonial, enquanto ação específica da razão subalterna, encena-se como um caminho e um esforço em direção à libertação das vidas segregadas da \na fronteira, incluindo as memórias subalternas desses sujeitos e suas respectivas histórias locais.

Considerando que uma teorização de ordem biográfica fronteiriça resulta de uma prática crítica incluída tanto na gnose liminar, quanto na razão subalterna, vale a pena determo-nos em tais conceitos, mesmo que de forma breve. Antes, porém, vale pontuar que não me detenho em tais conceitos, repetindo-os, simplesmente porque acredito que eles possam dar conta de contemplar a discussão crítica que proponho de meu lócus específico, qual seja, senão a fronteira-Sul que compreende meu lócus de enunciação e, por conseguinte, o lugar de onde penso, trabalho e vivo. Valho-me de tais conceitos, entre outros, porque acredito que eles podem endossar e contemplar, de forma crítica mais satisfatória, a discussão epistemológica específica demandada pela zona de fronteira que também produz saberes que geram suas próprias teorizações e formulações conceituais. Com isso, estou afirmando, entre outras abordagens não menos comprováveis, que não basta mais, enquanto crítico, nos aproximar de teorias e de conceitos que traduzam mais de perto a problemática epistemológica de um lugar de enunciação específico como, por exemplo, a fronteiraSul de onde erijo minha discussão. Também é necessário que se atente para as marcas do lócus e do bios que vêm incrustadas tanto nos corpora das produções culturais, quanto nas formulações conceituais emanadas dessas produções por meio de uma produção de conhecimento outro. Deve-se atentar, ainda, para a proposta político-epistemológica dos projetos subalternos intelectuais, bem como de seus respectivos autores, saídos desses lugares esquecidos e relegados à exterioridade, pela civilização ocidental. Uma teorização de ordem biográfica fronteiriça, como estou propondo aqui, não menospreza os saberes advindos da vida do local em questão, mesmo quando se tem consciência de que já existe toda uma articulação epistemológica outra pensada desses lugares outros que permaneceram no fora do 
sistema colonial moderno. A essa altura da reflexão proposta para o problema em questão, não se incorre mais no risco de cair em bairrismo, ou provincianismo, sobretudo por que a Natureza (que nem precisava ser em maiúscula) também produz saberes ecoepistemológicos que ainda não foram encampados pela ignorância humana. ${ }^{4}$

Acerca da razão subalterna, Mignolo a conceitua como "um conjunto diverso de práticas teóricas emergindo dos e respondendo aos legados coloniais na interseção da história euro-americana moderna." (MIGNOLO, 2003, p. 139) Entendo, assim, que uma crítica de ordem biográfico-fronteiriça, como a que proponho aqui, apresenta-se e se sustenta como uma prática teórica que emerge do arrabalde da fronteira-sul por ser capaz de, a seu modo, barrar a crítica migrante dos centros, bem como seus respectivos conceitos erigidos no interior da aldeia global para representar, por meio de uma interpretação textual e estetizante, o que é da ordem da exterioridade, por mais que esta seja uma invenção daquele mundo interior. As práticas teóricas subalternas tendem a emergir das bordas, cada vez mais, para barrar as histórias, as teorias e as críticas de caráter acadêmico e disciplinar que ainda, em pleno século 21, apesar de cada vez menos, teimam em se hospedar na casa da anfitriã na tentativa universalizante e hegemônica de subestimar a produção de saberes e de subjetividades específicas que encenam nas bordas por meio da representação, cada vez maior, das histórias locais fronteiriças. Na mesma direção, Mignolo, após reconhecer que a razão subalterna nutre e é nutrida por uma "prática teórica", afirma que ela

\footnotetext{
${ }^{4}$ Remeto o leitor para o texto "Para além do pensamento abissal: das linhas globais a uma ecologia de saberes", de Boaventura de Sousa Santos. (SANTOS \& MENESES (Orgs.), 2010, p. 31-83) "Na ecologia de saberes cruzam-se conhecimentos e, portanto, também ignorâncias. Não existe uma unidade de conhecimento, como não existe uma unidade de ignorância. As formas de ignorância são tão heterogêneas e interdependentes quanto as formas de conhecimento. Dada esta interdependência, a aprendizagem de certos conhecimentos pode envolver o esquecimento de outros e, em última instância, a ignorância destes. Por outras palavras, na ecologia dos saberes, a ignorância não é necessariamente um estado original ou ponto de partida. Pode ser um ponto de chegada. Pode ser o resultado do esquecimento ou desaprendizagem implícitos num processo de aprendizagem recíproca. Assim, num processo de aprendizagem conduzido por uma ecologia de saberes, é crucial a comparação entre o conhecimento que está a ser aprendido e o conhecimento que nesse processo é esquecido e desaprendido. A ignorância só é uma forma desqualificada de ser e de fazer quando o que se aprende vale mais do que o que se esquece. A utopia do interconhecimento é aprender outros conhecimentos sem esquecer os próprios. É esta a tecnologia da prudência que subjaz à ecologia de saberes. Ela convida a uma reflexão mais profunda sobre a diferença entre a ciência como conhecimento monopolista e a ciência como parte de uma ecologia de saberes." (SANTOS \& MENESES. (Orgs.), 2010, p. 56)
} 
é aquilo que surge como resposta à necessidade de repensar e reconceitualizar as histórias narradas e a conceitualização apresentada para dividir o mundo entre regiões e povos cristãos e pagãos, civilizados e bárbaros, modernos e pré-modernos e desenvolvidos e subdesenvolvidos, todos eles projetos globais mapeando a diferença colonial (MIGNOLO, 2003, p. 139-140).

Entende-se, por conseguinte, que somente por meio dessa "prática teórica" chamada de razão subalterna podemos subverter as leituras interpretativas canonizantes, estetizantes e modernizantes que, por sua vez, ancoradas numa visada crítica dualista, reforçam o colonialismo crítico excludente e sumariamente preconceituoso que ainda pensa poder determinar as regras da atribuição de sentidos e de interpretações nesse mundo regido, cada vez mais, pela diferença colonial. Aqui na fronteira-Sul, mas poderia ser em qualquer outro lugar, mas o deixa de ser por ser de onde estou propondo minha discussão crítica, os conceitos advindos dos grandes centros do país e do mundo, os discursos críticos e teóricos migrados, precisam ser repensados e reconceitualizados porque, somente por meio dessa prática de teorização descolonial, as histórias locais fronteiriças passam a tomar parte da reflexão crítica erigida desse lócus e, por extensão, as produções culturais deixam de ser interpretadas como objetos inertes da cultura e são inseridos na discussão crítica como produtores de conhecimentos outros. Vemos, por fim, na esteira da discussão proposta por Mignolo, que a razão subalterna subverte a razão moderna que imperou no mundo por meio do sistema colonial moderno.

Já sobre gnose liminar, Mignolo o conceitua como "um outro pensamento a partir e para além das disciplinas e da geopolítica do conhecimento, embutidas nos estudos de área; a partir e para além dos legados coloniais; a partir e para além das divisões de gênero e prescrições sexuais; e partir e para além dos conflitos raciais". (MIGNOLO, 2003, p. 140) Nessa direção, podemos entender a gnose liminar como uma extensão conceitual de razão subalterna, na medida em que para ambos os conceitos o pensar a partir de e para além de qualquer visada disciplinar tornam-se determinantes. Daí, pensar a partir da fronteira-Sul, como estou propondo aqui, e cujo pensamento assenta-se em teorías sin disciplina ${ }^{5}$, embasa e sustenta a reflexão

\footnotetext{
${ }^{5}$ Faço alusão ao título do livro Teorías sin disciplina (latinoamericanismo, poscolonialidad y globalización em debate), organizado por Santiago CastroGomez y Eduardo mendieta.
} 
crítica gnosiológica subalterna fronteiriça como um anseio de ultrapassar a subalternidade e um elemento para a construção de formas subalternas de pensar. Assim, por meio de uma teorização fronteiriça, parece ser possível erigir uma crítica da mesma ordem que, por sua vez, permite ao crítico, e a todos os sujeitos envolvidos no lócus em questão, negociarem suas vidas e sua condição subalterna, bem como construírem outras formas de pensar as vidas na fronteira e, por conseguinte, julgar as produções culturais desse lócus envolvido. Mais importante do que o domínio desse lócus territorial, torna-se o domínio crítico desse lócus epistemológico fronteiriço aqui em destaque, uma vez que sobressaem dele sensibilidades locais e biográficas que fazem toda a diferença na leitura crítica pretendida. Sempre na direção do que postula o autor de Histórias locais $\backslash$ Projetos globais, pensar a partir da fronteira implica a escolha de adotar o pensamento liminar que congrega tanto a razão subalterna quanto a gnose liminar como forma de romper a epistemologia moderna que grassou pelo mundo afora e ainda quer interferir na possibilidade de pensar nas e a partir das margens de um modo geral. E não por acaso aqui surge um conceito que faz toda a diferença numa discussão de ordem biográfica fronteiriça. Trata-se do de diferença colonial que, segundo o autor, nada mais é do que "a classificação do planeta no imaginário colonial\moderno praticada pela colonialidade do poder: uma energia e um maquinário que transformam diferenças em valores." (MIGNOLO, 2003, p. 37) Quando se pensa a partir dos locais biográficos e epistemológicos, ou melhor, quando se pensa a partir da fronteira, é possível subverter a dialética dualista da modernidade, na qual existia apenas a forma de pensar sobre (o outro) e, por conseguinte, não previra a possibilidade de pensar $a$ partir de. Já que estamos no campo minado da teoria, entendemos que somente uma teorização fronteiriça permite a inscrição de um novo sujeito epistemológico que pensa a partir das e sobre as fronteiras, como postula Mignolo. Assim, dessa perspectiva, se consegue romper a epistemologia moderna e compreender descolonialmente os sujeitos e as produções imbricados no lócus fronteiriço.

\section{Entre bugres e bios no front ${ }^{6}$}

\footnotetext{
${ }^{6}$ Ver meu texto "OS CONDENADOS DA FRONTEIRA".
} 
La frontera, em otras palabras, está em la barra que separa y une modernidad \colonialidad (MIGNOLO, 2010, p. 121).

A crítica local praticada aqui nessa banda sudoeste do país não é em nada fronteiriça, apesar de termos até uma fronteira territorialmente falando, uma vez que essa crítica continua ignorando tal paisagem, sobretudo a paisagem epistemológica do lugar, fazendo questão de permanecê-la na ignorância crítica. A paisagem epistemológica daqui não passa de um mundo sombrio, pantanoso e relegado à escuridão, pelo simples fato de a crítica local fazer questão de continuar a não ver e a não considerar uma epistemologia fronteriza ${ }^{7}$ que irrompe de todos os lados e se materializa em muitas produções artísticas da cultura local fronteiriça. Não basta que a crítica seja feita dessa banda fronteiriça, territorialmente delimitada, do país para que tal crítica seja considerada como uma crítica fronteiriça. Antes de mais, é preciso que a crítica dessa zona fronteiriça se predisponha a pensar a partir da insígnia fronteira, a partir das sensibilidades locais e biográficas dos sujeitos e das produções do lugar, a partir das memórias, dos discursos e dos saberes, a partir das linguagens, a partir das histórias locais subalternas, enfim, a partir do conhecimento e dos conceitos que se constroem do lócus epistemológico fronteiriço.

Se a fronteira está na barra que separa e une modernidade \colonialidade, como se lê na epígrafe aposta, então podemos entender a crítica biográfica fronteiriça como a barra, que aproxima e afasta o bios e o lócus, como o espaço, que hospeda e rechaça o outro, enfim, o que é da ordem da crítica biográfica fronteiriça não passa de uma paisagem compósita e porosa do que entendemos por fronteira (Sul). Sem perder o "contacto" com a luta diária entre a "retórica de la modernidad y la lógica de la colonialidad", a fronteira-Sul, portadora de muitas histórias locais próprias e alheias, habita sua específica fronteira, sua própria linguagem, sua própria memória, sua teoria política e econômica, e todas elas marcadas com "pegadas" do local fronteiriço. Mais do que saber disso, a crítica biográfica fronteiriça precisa partir dessa discussão, em cujo lugar fronteiriço se encontram o local e sua relação de dominação e exploração de dominação por parte do pensamento moderno, como forma de não mais reforçar uma universalização (regionalização) do regional levado

\footnotetext{
${ }^{7}$ VER ANZALDÚA. Borderlands $\mid$ La frontera: the new mestiza.
} 
a cabo com insistência da crítica moderna. Na esteira do que discute Mignolo em Desobediência epistémica (2010), a fronteira-Sul aqui em destaque, enquanto portadora e espaço de histórias locais, se, por um lado, mostra sua pluriversalidade enquanto uma história local, por outro lado, trabalha no sentido de que sua história local descolonizadora se conecte por meio de sua experiência comum e a utilize como base para a constituição de uma nova lógica comum do "conhecer": o pensamento fronteiriço. Enfim, como se percebe, o pensamento fronteiriço advém dessa experiência das histórias locais articuladas na fronteira, das vivências dos sujeitos nela imbricados, das relações pluriversais estabelecidas nesse espaço bios fronteiriço descolonial. "Se trata de uma conciencia de 'frontera”, teria afirmado Anzaldúa (Apud MIGNOLO, 2010, p. 107).

É nesse sentido que uma crítica de ordem biográfica fronteiriça, como a postulada aqui, deve entender e propagar que o pensamento fronteiriço não passa de um método para protagonizar a virada descolonial (MIGNOLO) proposta por tal crítica. Um método, grosso modo, que propõe teorizações, inclusive como forma de dialogar com a visada universal imposta pelo pensamento moderno, ao invés de se prender a um modelo crítico disciplinar. Teorías sin disciplina poderia ser a rubrica que contorna a teorização pluriversal que sustenta o pensamento crítico fronteiriço por excelência. De acordo com Mignolo, "el pensamiento fronterizo se convierte em un método necesariamente crítico y descolonial em lós proyectos epistêmicos y políticos, para colmar las brechas y de revelar la complicidad imperial que vincula la retórica de la modernidad com la lógica de la colonialidad." (MIGNOLO, 2010, p. 125)

Em torno da fronteira-Sul encontramos povos e produções culturais que, a seu modo, põem em prática esse método fronteiriço desde as fissuras, ou entranhas de seus corpos marcados pelas especificidades culturais do lócus fronteiriço. Penso nos Bugres esculpidos tanto por Conceição dos Bugres, quanto nos que continuam a ser esculpidos por Mariano Neto, endossando ambos a rubrica de uma arte plástica bugresca local. ${ }^{8}$ Penso também no Balaio de Bugre (1992) crioulista do escritor fronteiriço Helio Serejo que não para de exteriorizar pequenas histórias locais sulinas por meio de seu amor irrestrito das coisas charruas, nativistas, avoengas e bugrescas

\footnotetext{
${ }^{8}$ VER PAISAGENS BIOGRÁFICAS PÓS-COLONIAIS: retratos da cultura local sul-mato-grossense (2014), de Marcos Antônio de Oliveira.
} 
desse lócus fronteiriço. Mas penso ainda no quadro (2013) ${ }^{9}$ pintado por Hilton Silva no qual o artista-filho retrata o espaço-arquivo em que a mãe escultora Conceição dos Bugres vivia e, por conseguinte, esculpia seus Bugres na madeira. Esse trabalho de Hilton, especificamente, capta o lado sombrio de um povo tangido para a fronteira e relegado ao esquecimento de uma cultura moderna que levou a prática da exclusão às suas últimas consequências, sobretudo por estar assentada numa visada messiânica e salvífica do "isto é bom para todos!". Todos esses filhos (da meia noite da fronteira-Sul) e representantes legítimos do lugar fronteiriço trazem amalgamados em seus corpos (por meio de heranças e errâncias) o bios e o lócus (biolócus) de uma vida vivida, ou passada na fronteira-Sul. Aqui não se trata de subjetividades advindas da Psicanálise, ou até mesmo da Teoria do Discurso assentada na figura de um sujeito que foi sendo desconstruído até o longo século XX. Trata-se, antes, de subjetividades outras que passam por um biolócus específico e atravessado por questões de ordem espacial que não foram contempladas pela epistemologia moderna que não fez outra coisa senão supervalorizar sua interioridade absoluta.

Soma-se a esse conceito de biolócus, no qual se privilegia, sobretudo, o bios e o lócus das produções culturais artísticas e seus respectivos produtores, o conceito de biovarismo, como forma de consolidar de vez a presença e a importância do crítico na teorização biográfica fronteiriça. Reporto-me ao texto "Madame Bovary somos nós”, de Eneida Maria de Souza, para avançar sobre esse conceito que amarra as pontas de uma crítica de ordem biográfica (e) fronteiriça. Se, no campo da crítica biográfica, o bovarismo se traduz em torno de situações pessoais vividas, entre sujeitos e personagens, criadas pela ficção, em cujas relações ocorre uma verdadeira troca de papeis, travestindo-se ambos de um caráter subjetivo e de ilusão romântica, o biovarismo, por sua vez, enquanto discussão teórica advinda da crítica biográfica fronteiriça, reconhece o atravessamento de sujeitos e de objetos em sua discussão, mas por nenhum momento funde, tomado por uma subjetividade discursiva, os bios e os lóci dos envolvidos. Aqui, as heranças bioculturais se sobrepõem às heranças coloniais. Parodiando o belo e sugestivo título do ensaio de Eneida, "Madame Bovary somo nós", reconheço que a fronteira somos nós, ou melhor, que nós somos a

\footnotetext{
${ }^{9}$ Ver reprodução do quadro em meu texto "OS CONDENADOS DA FRONTEIRA", p. 49.
} 
fronteira, e essa afirmação emblematiza o gesto crítico de que todos daqui da fronteira-Sul habitamos numa convivialidade na qual a hospitalidade nem sempre é hospitaleira como tão comumente se pensa, habitamos um lócus no qual os bios se roçam sem se misturar, uma vez que a cultura local fronteiriça sul-mato-grossense sofre de um processo transculturador continuum sem cair na hibridização, habitamos um lugar que fomenta uma teorização que privilegia as "semelhanças-na-diferença" (MIGNOLO), ao invés de privilegiar, por exemplo, as semelhanças instauradas entre personagens e crítico defendidas pelo bovarismo crítico para o qual tudo converge para uma ficção romanesca. A fronteira, enquanto um espaço gnosiológico fronteiriço, barra as teorias modernas acerca da subjetividade humana, e em seu lugar prefere falar em especificidade, em singularidade, em semelhanças-nadiferença colonial.

\section{Balaio de Bugre e pensamento crioulo}

Vivi, intensamente, esses momentos, formadores todos do crioulismo embriagador. (SEREJO, "Amor pelo crioulismo", p. 35)

Muito - muito mesmo - de CRIOULISMO, no labutar ervateiro. Talvez seja o mais autêntico de todos, por ser mescla de XUCRISMO, CASTELHANO, GUARANI, MODISMO E EXPRESSÕES FRONTEIRIÇAS. (SEREJO, "Das coisas crioulas", p. 146)

Do matuto, do sertanejo, do charrua, do campachano e do CRIOULO dotado de fascinação, nada balançou tanto o meu coração de fronteiriço e de bugre, como a "árvore dos ninhos", pelo excêntrico, compactação clorofilada, originalmente paisagística, graciosidade e beleza. (SEREJO, "Isto também é crioulismo", p. 164)

Quero, aqui, mesmo que de forma breve, abrir o arquivo Balaio de Bugre (1992) do intelectual fronteiriço crioulo Helio Serejo e rastrear o modo como o escritor redesenha a paisagem, sempre em formação, do lócus fronteiriço crioulo aqui denominado de fronteira-Sul. Atendo-me, antes de tudo, ao biolócus, vejamos como o próprio artista fronteiriço se autodenominava: 
Eu sou o homem desajeitado e de gestos xucros que veio de longe. Eu sou o homem fronteiriço que, na infância atribulada, recebeu nas faces sanguíneas os açoites desse vento, vadio e aragano, que, no afirmar da lenda avoenga, nasce nas terras incaicas, num recôncavo do mar, varre o altiplano boliviano, penetra o imenso aberto do Chaco Paraguaio, para depois, exausto do bailado demoníaco, numa cólera e estrupício de tormenta, arrebentar, cortante e gélido, na cidade de Ponta Porã, a Princesa da Fronteira, sentinela avançada das terrarias mato-grossenses. Eu vim dos ervais, meus irmãos, do fogo dos "barbacuás", do canto triste e gemente dos "urus", dos bailados divertidos, dos entreveros dos bolichos das estradas, do mais hirsuto da paulama seca, do pôr-do-sol campeiro, dos dutos, das encruzilhadas e das distâncias perdidas. Eu sou filho da "jungle", sou gaudério de todos os pagos, apaixonado das querências e cria de todos os galpões da terra. Eu vim de longe, eu sou um misto de poeira de estrada, de fogo de queimada, de aboio de vaqueiro, de passarada em sarabanda festiva no romper da madrugada, de lua andeja rendilhando os campos, as matas, as canhadas, o vargedo. Sou misto, também, de índio vago, cruza-campo e trota-mundo (SEREJO, 1992, p. 7).

Antes, porém, de se apresentar por meio dessas "palavras do prosador crioulo...", ao justificar o titulo do livro Balaio de bugre, Serejo se reconhece como "Bugre legítimo, com arremedos de homem civilizado!" (SEREJO, 1992, p. 5) Transcrevo esta sutil passagem porque quero entender que as palavras do prosador crioulo, transcritas acima, bem como toda a produção cultural do intelectual fronteiriço, desfazem essa imagem contraditória de um bugre legítimo com arremedos de homem civilizado. Bugre legítimo, sim, nativo e crioulo com certeza, mas sem qualquer ranço de homem civilizado letrado. Em se tratando do escritor que fora Helio Serejo, e sua obra esta aí para comprovar, quero acreditar que o que o leva a tal constatação é sua consciência fronteiriça, mesmo que trabalhada numa sutil ironia; afinal, "bugre briga e morre para defender o seu balaio. Tem-lhe estima imensa. É jóia preciosa que a natureza lhe deu", como ele mesmo diz na Apresentação que faz ao livro para justificar seu título.

Encontramos de tudo dentro do balaio-arquivo de Serejo, desde figuras emblemáticas da fronteira, como o andariego, o galponeiro, o povuero, até objetos como o porongo e o couro seco de vaca, sem excluir o urutau, a saudade e a paisagem específica da fronteira. Mas entre todos os objetos, coisas e figuras, é seu "Amor pelo 
crioulismo"10 que não apenas vai respaldar sua obra como uma das mais importantes da fronteira-Sul, como também vai permitir que a crítica fronteiriça, por meio dela, trate com mais propriedade de questões intrínsecas à cultura local fronteiriça sulmato-grossense, como a temática do crioulismo, da natureza e da fronteira, de uma epistemologia fronteiriça, por exemplo.

Em Serejo, o crioulo é sempre o nativo. Para ilustrar essa afirmação, detenhome no texto "Poronguito" que, não por acaso, traz a figura do porongo como o que pode haver de mais crioulo em toda a poética fronteiriça do autor. Para ele, o porongo é o mais crioulo de todos os porongos do Brasil, "porque é filho legítimo das capoeiras, arrenegando sempre os estirões de unidade, é surpreendente patuá caseiro porque enfeixa alegria e sorte em seu bojinho gracioso." (SEREJO, 1992, p. 14) Reconhece o poronguito como importante, "porque é nativo [...], por ser crioulo, verídico, portanto, sem mistura alguma de 'cria de fora.'” (SEREJO, 1992, p. 14) Sem "cria de fora" pode soar, a princípio, bastante contraditório, posto que a fronteira é de natureza porosa, sem lados, sem dentro nem fora, lugar por onde os andariegos e os vindo de longe transitam; mas uma fronteira territorial não basta. É preciso uma fronteira de ordem epistemológica. Ou melhor, mais do que isso: sem se levar em conta a diferença colonial inscrita nos lugares fronteiriços, nos povos e nas línguas, não se é possível falar de crioulismo. Logo, a poética de Serejo nos ensina, desde o início, que falar a partir do crioulismo nesse lócus fronteiriço é levar em conta a diferença colonial que se encontra nas encruzilhadas da fronteira e dos conflitos por terra, por exemplo, que se extravasam por todos os lados da fronteira-sul. 0 crioulo em Serejo pode ser e é o nativo, mas a fronteira é rodeada pelo sistema colonial moderno que a comprime por todos os lados, relegando os sujeitos crioulos nativos a um mundo sombrio e esquecido sem precedentes na história moderna do ocidente, lugar não por acaso onde o sol se põe.

Walter Mignolo, na parte intitulada “A 'créolité' e o pensamento liminar", constante de seu livro Histórias locais $\backslash$ Projetos globais (2003), discute longamente sobre o conceito de crioulo e crioulismo na América e fora dela e, apesar de sequer mencionar o Brasil, é quem melhor nos ajuda a compreender a temática acerca do crioulismo presente na poética de Helio Serejo e, por extensão, um assunto

10 “Amor pelo crioulismo" é título de um texto que se encontra no livro Contos crioulos, p. 35-36. 
nativo na \da fronteira-sul. Quando denomino o pensamento de Serejo de um pensamento crioulo, estou apenas aproximando-o de outra possível rubrica para o "pensamento liminar" criado por Mignolo. Não por acaso, o próprio Mignolo sugere tal aproximação. Segundo a discussão feita pelo crítico, epistemologicamente o crioulismo não passa de uma "forma particular de pensamento liminar, oriundo de uma história local particular do sistema mundial moderno". (MIGNOLO, 2003, p. 328) E é como uma história local particular situada na \da fronteira-sul que vemos e entendemos como se inscreve e se desenvolve o crioulismo dentro da obra de Serejo e na exterioridade do lócus geoistórico em questão. Se devemos entender a tradição não como algo "anterior" à modernidade, mas como a persistência da memória (Ver MIGNOLO, 2003, p, 98), como postula Mignolo, então fica-nos mais fácil de compreender o modo como Serejo dialoga com as memórias subalternas e as histórias locais da fronteira onde ele nasceu e viveu e continuou a atravessá-la pelos restos de seus dias:

Porque viver o crioulismo é o cristão tornar-se guri novamente. Guri de invencionices e muitas artes, pelos campos verdes, lombadas e chapadões ornados de capim nativo. Eu te saúdo, poronguito fronteiriço, com as minhas carinhosas recordações, e o bem-querer que ainda tem morada na sensibilidade do coração caboclo! (SEREJO, 1992, p. 16)

As sensibilidades do coração caboclo amalgamam tanto as sensibilidades locais quanto as biográficas do escritor da fronteira. Consignam o lócus e o bios por meio de um gesto de trazer de volta ao coração (recordar). Atestam, por sua vez, que o crioulismo pode ser inseparável das sensibilidades do local geoistórico fronteiriço e que esse local, de alguma forma, fora marcado pela presença do crioulismo. As sensibilidades crioulas não estão arraigadas ao nascimento dos indivíduos bugres da fronteira-sul, nem muito menos se reportariam a uma possível origem da fronteira; antes se explicam, se formam e se transformam, se criam e se perdem no decorrer da vida (MIGNOLO) desses indivíduos e dentro de sua própria família. E lembramos, de acordo com Said, que "todas as famílias inventam seus pais e filhos, dão a cada um deles uma história, um caráter, um destino e até mesmo uma linguagem". (SAID, 2004, p. 19) As famílias da\na fronteira inventam seus pares a partir de seu lócus, de seu bios, a partir de sua linguagem e a partir desse lugar escolhido ganham uma 
identidade e formam a consciência fronteiriça de si mesma e dos outros. Adverte-nos Mignolo de que "as sensibilidades dos locais geoistóricos relacionam-se com um certo sentido de territorialidade (que nunca se perde) [...] e inclui a língua, o alimento, os odores, a paisagem, o clima e todos esses signos básicos que ligam o corpo a um ou diversos lugares." (MIGNOLO, 2003, p. 264) Duas questões importantes e imbricadas desdobram-se daí, inclusive como forma de melhor compreender tal relacionamento entre as sensibilidades dos locais geoistóricos e o sentido de territorialidade. Primeira, que local geoistórico não se refere apenas a um lugar geográfico específico, mas a um lugar geográfico que possua uma história local particular: a fronteira-sul, aqui compreendida pelo estado de Mato Grosso do Sul/Brasil e os países lindeiros Bolívia e Paraguai, não é nem a fronteira-Norte de meu próprio país (outros dialetos, povos, línguas, alimentos, odores, paisagens, clima, outros corpos, outras florestas, outros signos). Segunda, que toda e qualquer produção do conhecimento é inseparável das sensibilidades do local geoistórico (MIGNOLO), e talvez seja exatamente por isso que devemos tomar as produções artístico-culturais, não mais como objetos passíveis de análise e de dissecação visando satisfazer tão somente os egos de proeminentes críticos modernos, mas como corpos vivos que produzem conhecimento a partir de sensibilidades de um local geoistórico com sua história local particular.

Se uma planície é a extensão do corpo do indivíduo nela envolvido, como postula Borges por vários de seus contos policiais, então podemos entender a "planície da região sulina mato-grossense", de Serejo, como uma extensão de seu bios e, a seu modo, captada por meio de sua escritura. Sua paisagem campestre, nativa e crioula amalgama bios e lócus do homem da fronteira e traduz por meio de uma memória subalterna ${ }^{11}$ um desejo de sobrevida: "mas não se me apaga da memória essa paisagem crioula, que ficou engastada em meus olhos e no coração. Jamais dela me separei. O seu crioulismo vive em mim. Morrerei com ela." (SEREJO, 1992, p. 28) Para Mignolo, “o crioulismo descreve um local territorial e geoistórico" (MIGNOLO, 2003, p. 330) e "se define como um modo de ser associado com a economia, e, mais especificamente ainda, com a economia de plantações". (MIGNOLO, 2003, p. 330) E

\footnotetext{
11 Ver o capítulo "IV MEMÓRIAS SUBALTERNAS LATINAS: ensaio biográfíco", constante no livro Perto do coração selbaje da crítica fronteriza, p. 131-159.
} 
como não se pensar aqui na figura do ervateiro, também conhecido por "índios guaranis ou bugres paraguaios', que se encontra em toda a poética fronteiriça de Serejo; ou na do povuero, aquele que nasceu e viveu no lugar e que é apaixonado pelas paisagens crioulas, que faz parte da história do xucrismo e que ajudou a construir a pátria charrua ${ }^{12}$; ou na figura do galponeiro, aquele que é a imagem autêntica do crioulismo, o símbolo da vivência charrua e a estátua aragana do xucrismo $^{13}$; ou na do andariego, aquele andarilho sem destino certo e que deixou o seu rastro ao longo da fronteira para marcar a caminhada de inúmeros martírios, (SEREJO, 1992, p. 116) - todas figuras araganas emblemáticas, entre outras, da vasta fronteira-sul crioula que se encena no entrecruzamento de povos, línguas, territórios, nacionalidades, memórias, religiões e de várias histórias locais.

0 pensamento crioulo que, grosso mudo, sustenta uma discussão proposta pela crítica biográfica fronteiriça aproxima-se, como já disse, do pensamento liminar de Mignolo. Sobretudo na medida em que aquele se encontra reprimido pelo domínio da hermenêutica e da epistemologia enquanto palavras-chave que controlam a conceitualização do saber. (Ver MIGNOLO, 2003, p. 49) Situado dentro do sistema mundial moderno, sua saída estratégica esta na proposição de uma epistemologia outra, aqui fronteiriça ou crioula, como forma de barrar a imperialidade dos discursos hegemônicos e dos conceitos modernos que grassam nas bordas do fora. Se a cultura está para a paixão, enquanto a civilização está para a razão, como aprendemos em Mignolo, então também é tarefa do pensamento crioulo rearticular “'a razão universal da civilização' do ponto de vista subalterno da 'razão cultural', desde que em 'cultura' incluamos um componente epistemológico." (MIGNOLO, 2003, p. 68) Por meio dessa rearticulação é possível também contar histórias locais a partir das fronteiras do moderno. Trata-se, claro, de histórias "esquecidas", negadas, enterradas vivas, fronteiriças por excelência, as quais propõem uma epistemologia fronteiriça: "uma epistemologia da, e a partir da, margem do sistema mundial colonial \moderno, ou, se quiserem, uma epistemologia da diferença colonial que é paralela à epistemologia do mesmo." (MIGNOLO, 2003, p. 83) Na esteira do pensamento liminar de Mignolo, o pensamento crioulo só pode localizar-se na

\footnotetext{
12 "Sinto grande orgulho de ser povuero", afirmou Serejo no texto "Povuero".

${ }^{13}$ SEREJO. “O'galponero legítimo', filho do criulismo xucro, que não respeita fronteiras". Balaio de bugre, p. 52.
} 
fronteira do sistema e quando se leva em consideração diferentes histórias locais. É escusado dizer que tal reflexão não se limita à fronteira territorial; antes, e pelo contrário, trata-se de uma fronteira epistemológica, como forma de barrar aquela subalternização do conhecimento alimentada à exaustão pela razão moderna ocidental. (Cf MIGNOLO, 2003, p. 103) O pensamento liminar, ou, como o prefiro, o pensamento crioulo

traz para o primeiro plano a irredutível diferença epistemológica entre a perspectiva a partir da diferença colonial e as formas de conhecimento que, sendo críticas da modernidade, da colonialidade e do capitalismo, permanecem "dentro" do território, "sob custódia" dos "universais abstratos (MIGNOLO, 2003, p. 129-130).

\section{REFERÊNCIAS}

ANZALDÚA, Gloria. Borderlands $\mid$ La frontera: the new mestiza. São Francisco: Aunt Lute Books, 2008.

BORGES, Jorge Luis. O fazedor. Trad. de Josely Vianna Baptista. São Paulo: Companhia das Lestras, 2008.

CADERNOS DE ESTUDOS CULTURAIS: Brasil\Paraguai\Bolívia. Campo Grande: Editora da UFMS, 2015.

CADERNOS DE ESTUDOS CULTURAIS: povos indígenas. Campo Grande: Editora da UFMS, 2015.

CADERNOS DE ESTUDOS CULTURAIS: pós-colonialidade. Campo Grande: Editora da UFMS, 2013.

CADERNOS DE ESTUDOS CULTURAIS: crítica biográfica. Campo Grande: Editora da UFMS, 2010.

CADERNOS DE ESTUDOS CULTURAIS: memória cultural. Campo Grande: Editora da UFMS, 2013.

CADERNOS DE ESTUDOS CULTURAIS: fronteiras culturais. Campo Grande: Editora da UFMS, 2012.

CADERNOS DE ESTUDOS CULTURAIS: cultura local. Campo Grande: Editora da UFMS, 2011.

MIGNOLO, Walter. Histórias locais $\mid$ Projetos globais: colonialidade, saberes subalternos e pensamento liminar. Trad. de Solange Ribeiro de Oliveira. Belo Horizonte: Editora UFMG, 2003.

MIGNOLO, Walter. Desobediencia epistémica: retórica de la modernidad, lógica de la colonialidad y gramática de la descolonialidad. Buenos Aires: Ediciones Del Signo, 2010 (Coleccion Razón política - dirigida por Walter Mignolo). 
MIGNOLO, Walter. El vuelco de la razón: diferencia colonial y pensamiento fronterizo. Buenos Aires: Ediciones Del Signo, 2011. (Coleccion Razón Política - dirigida por Walter Mignolo).

MIGNOLO, Walter. "Postoccidentalismo: el argumento desde América Latina”. In: CASTRO-GOMEZ y MENDIETA, Eduardo (org.) Teorías sin disciplina:

(latinoamericanismo, poscolonialidad y globalización em debate). México: Miguel Angel Porrúa, 1998, s \n página.

NOLASCO, Edgar Cézar. "Crítica biográfica fronteiriça (BRASIL \PARAGUAI \BOLÍVIA)”. In: CADERNOS DE ESTUDOS CULTURAIS:

Brasil \Paraguai\Bolívia. Campo Grande: Editora da UFMS, 2015, p. 47-63.

. "Os condenados da fronteira”. In: CADERNOS DE ESTUDOS CULTURAIS: povos indígenas. Campo Grande: Editora da UFMS, 2015, p. 39-54.

NOLASCO, Edgar Cézar. Perto do coração selbaje da crítica fronteriza. São Carlos: Pedro \& João Editores, 2013.

OLIVEIRA, Marcos Antônio de. Paisagens biográficas pós-coloniais: retratos da cultura local sul-mato-grossense. Campinas, SP: [s.n.], 2014. (Orientador: Mauricius Martins Farina. Tese (doutorado) - UNIVERSIDADE ESTADUAL DE CAMPINAS, Instituto de Artes).

PESSANHA, Juliano Garcia. Ignorância do sempre. São Paulo: Ateliê Editorial, 2000.

SAID, Edward W. Fora do lugar: memórias. Trad. de José Geraldo Couto. São Paulo: Companhia das Letras, 2004.

SANTOS, Boaventura de Sousa. "Para além do pensamento abissal: das linhas globais a uma ecologia dos saberes". In: SANTOS, Boaventura de Sousa, MENESES, Maria Paula (Orgs.). Epistemologias do Sul. São Paulo: Cortez, 2010, p. 31-83.

SEREJO, Helio. Balaio de bugre. Tupã: Gráfica e Editora Cingral, 1992. Edição especial. SEREJO, Helio. Contos crioulos. Campo Grande: Editora UFMS, 1998.

SOUZA, Eneida Maria de. "Madame Bovary somos nós". In: SOUZA, Eneida Maria de. Crítica cult. Belo horizonte: Editora da UFMG, 2002, p. 115-128. 